\section{Nachruf zum Tod von Werner Nordhaus}

7 um Tod von Werner Nordhaus, der Lam 11. Februar 2013 wenige Wochen vor seinem 70. Geburtstag gestorben ist, Auszüge aus einem Nachruf des ZVO-Geschäftsführers Christoph Matheis:

Die Nachricht vom Ableben von Werner Nordhaus traf uns alle schmerzlich und hat uns tief bewegt. Wir werden ihn in Erinnerung behalten als den Mann, dem die Galvanound Oberflächentechnik sehr viel zu verdanken hat. Der gebürtige Mittenwalder war der Motor der erfolgreichen Entwicklung von Unternehmen wie AHC und Betz-Chrom. Als Chef war er bei Kollegen, Kunden und Lieferanten gleichermaßen beliebt. Werner Nordhaus prägte in der Galvanotechnik den Begriff der "messbaren Qualität". Für diesen damals neuen Qualitätsbegriff hat Werner Nordhaus mit einer ihm eigenen Beharrlichkeit Zeit seines Berufslebens geworben. Mit seiner unternehmerischen Kompetenz, seiner Erfahrung und seinem fachlichen Wissen hat er für unsere Branche neue Impulse gesetzt und dazu beigetragen, Forschung und Praxis zu einer Einheit zu formen und unsere Branche zu einer gemeinsamen Sprache zu beflügeln. Werner Nordhaus war auch der Mann, der den DGO-Jahrestagungen die soziale und die gesellschaftliche Note verlieh. Der Saal hielt den Atem an, wenn er auf der Trompete mit sehr viel Gefühl den MitternachtsBlues spielte. Beharrlich, durchsetzungsstark, entscheidungsfreudig, kompetent, visionär - so durften wir Werner Nordhaus in vielen Jahren der Verbandsarbeit kennen und schätzen lernen. Trotz seiner schweren Erkrankung hat er bis zuletzt am Verbandsleben teilgenommen. Wir werden Werner Nordhaus aber noch mehr als Menschen vermissen. Sein Engagement, sein verantwortungsvolles Wirken und seine menschliche Wärme wird uns immer ein Vorbild sein.

\section{JOW Mobile Zwischenlager in der Fertigung}
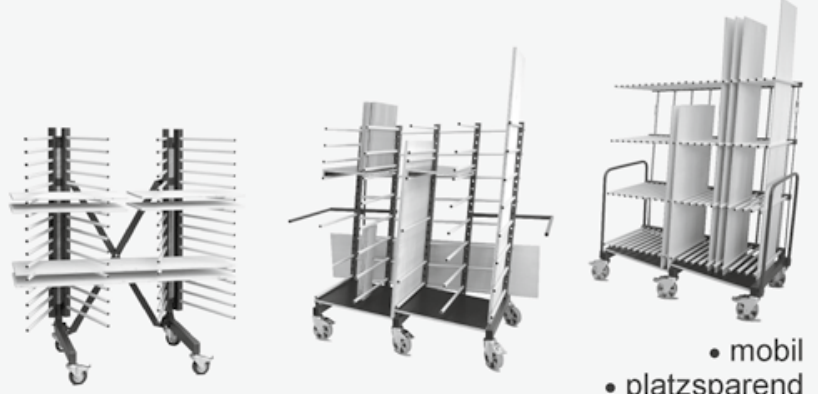

- mobil

- platzsparend

Tel.+43-2743/384480 office@jowi.at - einfach handhabbar

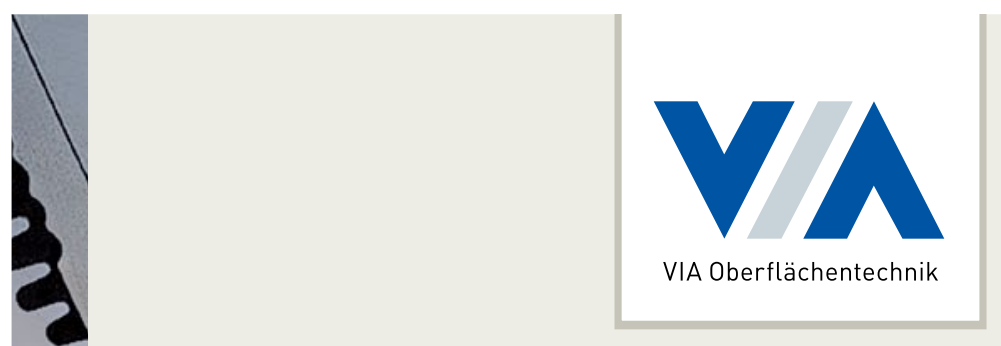

\section{Teile-}

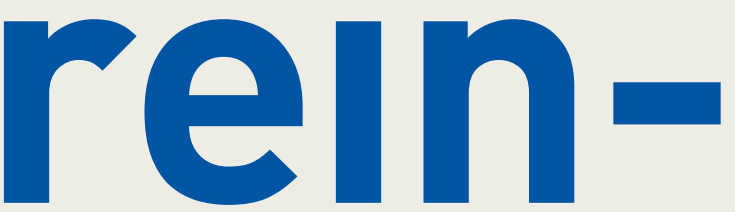

heit

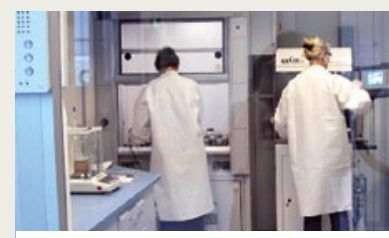

\section{Ihr Partner für Feinreinigung}

In unserem neuen, hochmodernen Kompetenzzentrum für Feinreinigung bieten wir Ihnen auf über 3000 qm Fläche unterschiedlichste Verfahren mit folgenden Reinigungsmedien:

\section{- DOWCLENE (modifizierter Alkohol) \\ - wässrig (alkalisch und sauer)}

- Kohlenwasserstoff

Alle Anlagen sind mit Reinraumanbindung. Fertigungsbegleitende Restschmutzanalysen nach VDA-Standard können im eigenen Labor durchgeführt werden.

Verlassen Sie sich auf eine termingerechte und prozesssichere Reinigungsqualität, die ihresgleichen sucht.
Entgraten

-Waschen

-Gleitschleifen

-Entfetten

-Feinreinigen

-Polieren

$-100 \%$-Kontrolle

-Verpacken

Unsere Leistungen für Sie: - Logistikservice
VIA Oberflächentechnik GmbH An der Chemischen 2 D-57368 Lennestadt-Grevenbrück
Telefon: 02721/9292-22

Telefax: 02721/9292-24

E-Mail: offtecav-i-a.de

Internet: www.via-feinreinigung.de 